\title{
Sobre la historia y la formación de los historiadores ${ }^{A}$
}

Para el historiador francés Marc Bloch hay un oficio del historiador. Oficio, en este contexto, alude a la realización de prácticas legadas por la tradición y perfeccionadas por ella, de la misma manera que en los oficios artesanales de la Edad Media se transmitían sus prácticas de maestro a discípulo. Es cierto que la Historia ha tenido este carácter por mucho tiempo. Se aprendía a escribir la historia leyendo libros de historia. Marc Bloch, fundador, junto con Lucien Febvre, de la Escuela de los Annales, una de las más prestigiosas de Europa, quería señalar con su afirmación algo que en una práctica de los historiadores podía parecer todavía válido. Sin embargo, no se limitaba a una mera aserción de carácter del carácter tradicional del oficio del historiador, sino que era consciente de cuántos elementos había incorporado la historia que, para él, Bloch, constituía ya una verdadera ciencia.

En Colombia, y en América Latina en general, el carácter de la Historia tiene todavía un sentido ambiguo de culto gratuito por el pasado y no ha logrado incorporar en su práctica aquellos elementos que sugieren en cierto momento una ruptura epistemológica (en lenguaje althusseriano) o, para usar la expresión de otro historiador francés, un umbral epistemológico. Ruptura, umbral, estas dos expresiones indican claramente una mutación de contenidos. Cómo, cuándo, se ha operado esta mutación, es un asunto que preocupa a los epistemólogos, y que significa que una práctica ideo-

A Entre los papeles de G. C. que tengo a mano encontré un largo texto — algo más de 30 páginas en máquina, papel tamaño carta, con numeraciones diversas - que parece ser un material de trabajo del que luego sacó varios artículos de diferentes extensiones con reflexiones sobre la disciplina histórica, sobre la historiografía, sobre el oficio y el papel del historiador, sobre la enseñanza y sobre el plan de estudios de su propio Departamento de Historia en la Universidad del Valle. Lo que copiamos aquí son unas cuantas páginas que Colmenares separó y publicó en Estravagario, suplemento del periódico El Pueblo de la ciudad de Cali, n. ${ }^{\circ}$ 1, enero 26 de 1975, 6-7. Más tarde, no sé por iniciativa de quién, puede que del propio historiador, esas reflexiones fueron incluidas en un volumen que preparó y editó para Colcultura Darío Jaramillo, bajo el título de La Nueva Historia (Bogotá: Instituto Colombiano de Cultura, 1975), 61-65. Es decir que el texto tuvo por lo menos tres formas de circulación: la copia en máquina de Colmenares, el texto publicado en Estravagario y el que finalmente se recogió en el volumen de Colcultura, que es el mismo de Estravagario. Hay que indicar que en la copia en máquina de Colmenares, en la primera página, se lee: "1. Sobre las prácticas históricas" - 10 páginas que no publicamos aquí y sobre las que hemos hablado brevemente en la presentación general de esta compilación-; luego, con numeración de página diferente se lee: "2. Algunas ideas sobre la reestructuración del Plan de estudios de Historia. 1. El oficio de historiador y la teoría histórica", que comienza con las palabras siguientes: "Para el historiador francés Marc Bloch...", es decir que corresponde al texto que aquí se publica, con una diferencia: el texto que apareció en Estravagario, luego publicado en el volumen de Colcultura, no recoge los párrafos que continúan la reflexión de Colmenares en su propia copia, que además incluye un numeral nuevo: “3. El tiempo de los historiadores", que copiamos, y se cierra con algunas definiciones y proposiciones en torno a "4. El programa de estudios", que dejamos de lado por su carácter específico en relación con las discusiones en la Universidad del Valle, condicionadas por una coyuntura académica y universitaria que es la de los años setenta y que poco tiene que ver con los actuales programas universitarios de formación de historiadores. Es muy posible que el corte del texto publicado por Colmenares en el año 1975 haya sido su propia decisión. 
lógica se convierte de pronto en un quehacer científico. Si se piensa seriamente que los programas de un Instituto de Historia deben rehacerse para acceder a este quehacer científico, debemos preguntarnos previamente por el carácter mismo de la historia. Desde el punto de vista de Bloch deberíamos preguntar también por la naturaleza del oficio peculiar en que se ocupan los historiadores.

Se dice que la Historia es una ciencia social. Que sea una actividad científica, cuyo objeto es la sociedad, implica cuestionar, anacrónicamente, el carácter de la historia como una de las bellas artes, en la cual bastaría para su elaboración conocimientos de tipo erudito, añadiéndose una cierta calidad literaria.

La ruptura, o si se prefiere, el umbral, establece la posibilidad de formular leyes científicas en el comportamiento histórico de los grupos sociales. La formulación de estas leyes no se deduce necesariamente de la observación empírica, sino de la reflexión teórica respecto de la sociedad. De acuerdo. Pero surge siempre el interrogante respecto a la capacidad del oficio, es decir, de la práctica habitual del historiador para alcanzar el nivel de una verdadera reflexión teórica. Así, frente al problema de una historia como ciencia surge el doble problema de conservar su naturaleza como práctica, la cual implica una larga tradición que le da su carácter peculiar frente a las otras ciencias sociales y, por otro lado, de dotarla de un verdadero cuerpo teórico que trascienda su práctica habitual.

Pero ¿existe o está conformada, en definitiva, una teoría histórica? En una polémica reciente Pierre Vilar sostenía que la misma historia marxista es una historia en construcción. Ciencia de totalidades, es decir, ciencia de síntesis. Como que se ocupa nada menos que de formular leyes de desarrollo histórico para las cuales no pueden excluirse variables que afectan de algún modo este desarrollo histórico.

La apariencia científica de otras ciencias sociales y su operatividad están dadas por el hecho de que pueden llenar sus cometidos, y en efecto los llenan más cabalmente en cuanto se limitan más, ateniéndose a unas pocas variables que pueden cuantificarse.

La economía, por ejemplo, puede operar inicialmente con las variables, perfectamente cuantificables, de oferta, demanda y precio. Pero ¿qué ocurre con la historia? Podemos acaso enmarcar un proceso histórico sumamente complejo como el de las formaciones sociales dentro de un modelo que contenga solamente variables demográficas cuantificables, o describirlo como la suma de meros procesos económicos. Naturalmente, frente a esta dificultad, ha sido siempre muy fuerte la tentación de reducir la historia a elementos puramente metafísicos y a una "teoría" cuya explicitación se limitaría a afirmar que hechos históricos antecedentes (no importa cuáles) son la "causa" de aquellos que los suceden; o que el hecho histórico ha sido engendrado por una voluntad individual que se identifica con un personaje al que se atribuye cualidades heroicas. Estos son los "fetiches" históricos que denunciaba François Simiand a comienzos del siglo [XX]. En América latina la historiografía apenas comienza a 
tener una posición crítica frente esos fetiches. Sin embargo, no puede decirse que haya surgido una escuela historiográfica propiamente latinoamericana. Ni que la investigación tienda de una manera definida hacia el esclarecimiento teórico de esas totalidades que son nuestras formaciones sociales.

Todo el mundo sabe que la investigación histórica en Latinoamérica es una actividad que se desarrolla marginalmente en academias cuya función principal es la definir la oportunidad de conmemoraciones patrióticas y cuyos miembros son llamados para premiar actividades intelectuales más o menos indefinidas en el periodismo o en la política. Los Estados no han creado centros de investigaciones históricas en los que se discuta el carácter científico de esta práctica. Por ende, la universidad parece atenida a los someros resultados de las academias, sin que tampoco cuestione verdaderamente estos resultados que son un producto ideológico. Para superar esta situación se hace necesario afirmar una y otra vez el carácter de ciencia de la historia y de ciencia social.

La pretensión más elemental de la ciencia, su pretensión de objetividad debe eliminar en la historia la mera afirmación ideológica para crear su objeto. Solo que este objeto no se da, ni puede darse, dentro de las coordenadas de unas pocas variables abstraídas de la realidad. La realidad a la que alude la historia como ciencia es la realidad total del hombre y la sociedad. Por eso es muy útil la concepción contenida en un pasaje de la Introducción a la crítica de la economía política [Marx, 1857], pasaje citado a cada rato, de que el conocimiento debe ir de la elaboración abstracta del concepto a lo concreto de la realidad. Pero ¿de dónde sacará el historiador todas las herramientas conceptuales que necesita imprescindiblemente para abordar el concreto histórico, es decir, la totalidad de lo social?

Esta pregunta nos remite de nuevo al hecho inescapable de que la historia es una ciencia de síntesis. De que la teoría de la historia no puede ser sino la resultante de la simbiosis entre elementos teóricos entresacados de análisis parciales del resto de las ciencias sociales y el cañamazo de los hechos históricos. El problema de las formas históricas particulares no puede resolverse sino mediante la confrontación de cada fenómeno que se da dentro de su estructura con un haz convergente del cuerpo teórico de todas las ciencias sociales.

Examinar, por ejemplo, la formación social capitalista del Valle del Cauca implica abordar aspectos de configuración geográfica, de desplazamientos de masas humanas, de su distribución en el campo y la ciudad en periodos largos de tiempo, de su densidad demográfica, de la manera como han jugado los elementos económicos de la actividad cotidiana en un modo de producción determinado, de las alteraciones de ese modo de producción, de las formas de subordinación en el trabajo, de los determinantes que están implícitos para estas actividades en la manera de distribución de los medios de producción, de las formas peculiares de conciencia de cada estrato social, etc. El problema de una formación social específica nos llevaría así a examinar algu- 
nos aspectos de los que suelen ocuparse la economía, la demografía, la sociología, la psicología social y la geografía humana ${ }^{\mathrm{B}}$.

La síntesis en historia puede verse también como la suma de investigaciones parciales, de carácter monográfico y regional, en las que se rescatan especificidades propias de una configuración histórico-social y sobre las cuales no cabe la generalización, sino que deben primero examinarse aisladamente, para ver qué papel juegan en un contexto global. No es lo mismo, ni puede reducirse a términos generales, por ejemplo, el desarrollo de una economía basada en el esclavismo y en algunas actividades agrícolas, con otra cuya base ha dado sobre formas de servidumbre o cuasi servidumbre, aunque el modo de producción haya sido también agrícola y basado en formas latifundistas.

\section{El tiempo de los historiadores}

Pero si puede renunciarse, provisionalmente, a contemplar la totalidad social en el espacio, no ocurre lo mismo con su dimensión temporal. Los aspectos fundamentales sincrónicos de cualquier formación social deben ser tenidos en cuenta so pena de mistificar y de falsear todo el proceso.

Una metodología histórica debería buscar por eso la identificación de los factores fundamentales de todo el proceso. Y la formación de historiadores debería ser capaz de suministrar todos los elementos teóricos que confluyan a la identificación y jerarquización de tales factores. La unidad de las ciencias sociales se refiere precisamente al hecho de que, a pesar de estar compartimentadas por una práctica académica, sus elaboraciones conceptuales tienen que apoyarse las unas en las otras para lograr una síntesis del saber. La historia, a diferencia de las otras ciencias sociales, maneja de una manera peculiar las categorías temporales. En cierto sentido podría decirse que es una ciencia de la temporalidad. A menudo se le reprocha que su reflexión teórica no haya clarificado suficientemente el problema, o, mejor, esta categoría de la temporalidad. Sin embargo, ninguna concepción histórica (a menos que así pueda llamarse la especulación que se conoce como filosofía de la historia) ha pretendido disociar la categoría tiempo, que es un mero vehículo, de los fenómenos materiales. Estos son históricos por cuanto se dan en el tiempo. Y de acuerdo con las especificidades de cada uno de ellos tenemos un ritmo propio de la sucesión temporal. Por ejemplo, según la concepción braudeliana, hay fenómenos de "larga duración". En estos fenómenos se inscriben aquellos cambios imperceptibles que van determinando una estructura y que no pueden ser medidos por una serie estadística la cual requiere una observación continuada. Por ejemplo, las transformaciones que se operan en un paisaje o en una estructura social como resultado del trabajo humano de siglos o de

B $\quad$ Aquí se detiene el texto publicado por Colcultura. 
un proceso de mestización. Otros conceptos temporales o del ritmo temporal están sugeridos por las fluctuaciones económicas de largo, mediano y corto plazo. En ambos casos, la geografía humana y la economía aportan su visión y su técnica peculiares a la comprensión de estos fenómenos.

La reflexión del historiador se encamina a establecer y a jerarquizar los momentos del cambio. La tarea de periodización no resulta así tan arbitraria como aparece a primera vista. Tradicionalmente ha sido, es cierto, un expediente escolar que distinguía entre los periodos que correspondían a una cultura o a una civilización. Pero por debajo de estos fenómenos aparentes han surgido otras formas de periodización que se atienen, no a la mera apariencia de dinastías y de formas culturales que se atribuyen a un pueblo, sino a fenómenos más fundamentales en la estructura de la producción y de las relaciones sociales. Esta concepción rompe con una mera sucesión cronológica para buscar similitudes en el tiempo en forma diacrónica, y que no están localizadas tampoco especialmente en una contigüidad.

La consideración sobre los ritmos temporales de larga y corta duración, de dinámica a corto y largo plazo, subordinan en la elaboración histórica elementos puramente circunstanciales, casi accidentes, que son los fetiches individuales y su comportamiento impredecible. Las leyes históricas solo pueden formularse así con respecto a una totalidad. La totalidad de la formación económico social con todos sus determinantes, que son el objeto de estudio del resto de las ciencias sociales.

$[\ldots]$ 